\title{
Determinación cuantitativa de la heterogeneidad en muestras de roca tipo plug usando tomografía computarizada de rayos $\mathrm{X}$
}

\author{
Alejandro Mendieta-Penagos ${ }^{1 *}$; Luis Reinaldo Rincón-Bautista ${ }^{1}$; Edwar Herrera-Otero ${ }^{2}$
}

DOI: http://dx.doi.org/10.18273/revbol.v41n1-2019007 @ (c)

Forma de citar: Mendieta-Penagos, A., Rincón-Bautista, L.R., y Herrera-Otero, E. (2019). Determinación cuantitativa de la heterogeneidad en muestras de roca tipo plug usando tomografía computarizada de rayos X. Boletín de Geología, 41(1), 133-149. DOI: 10.18273/revbol.v41n1-2019007

\section{RESUMEN}

La tomografía computarizada de rayos X (CT, por sus siglas en inglés), es una técnica que permite la inspección de la estructura interna de la roca de forma no destructiva a partir de imágenes de cortes obtenidos del escaneo de las muestras.

Este método ofrece una alternativa para la determinación cuantitativa de la heterogeneidad en el análisis de las muestras de roca tipo plug en lo que se refiere a porosidad, propiedad fundamental para definir el volumen de hidrocarburos presentes en el yacimiento y determinarla es una de las aplicaciones básicas de la CT. Donde, usando los coeficientes de atenuación de las imágenes CT se determina la heterogeneidad, con el fin de definir qué tan representativa es la muestra y garantizar la veracidad de los resultados en posteriores pruebas. En este caso, se determinó una alta heterogeneidad para las muestras sintéticas y una baja heterogeneidad para la muestra nativa.

El aporte significativo de esta innovadora metodología está relacionado con la visualización del interior de la roca de una forma no intrusiva, siendo este un método único que permite cuantificar la homogeneidad y calcular la porosidad del volumen total de la roca sin alterar la integridad de la muestra.

Palabras clave: Tomografía computarizada; plug; coeficiente de atenuación; heterogeneidad; porosidad.

\section{Quantitative determination of heterogeneity in samples of rock type plug using X-ray computerized tomography}

\begin{abstract}
The X-ray computed tomography (CT), is a technique that allows inspection of the internal structure of the rock in a non-destructive way from images of cuts obtained from the scanning of the samples.

This method offers an alternative for the Quantitative determination of heterogeneity in the analysis of samples of rock type plug in terms of porosity, a fundamental property to define hydrocarbons volume present in the reservoir and determining it is one of the basic applications of the CT. Where, using the attenuation coefficients of the CT images the heterogeneity is determined, in order to define how representative the sample is and guarantee the veracity of the results in subsequent tests. In this case, a high heterogeneity was determined for the synthetic samples and a low heterogeneity for the native sample.

The significant contribution of this innovative methodology is related to the visualization inside of the rock in a nonintrusive way, this being a unique method that allows to quantify the homogeneity and calculate the porosity of the total volume of the rock without altering the integrity of the sample.
\end{abstract}

Keywords: Computed tomography; plug; attenuation coefficient; heterogeneity; porosity.

${ }^{1}$ Modelamiento de Procesos de Hidrocarburos, Escuela de Ingeniería de Petróleos, Universidad Industrial de Santander, Bucaramanga, Colombia. (*) alejomendieta_@hotmail.com; rey.rinconbautista@hotmail.com

${ }^{2}$ Grupo de Investigación en Tomografía Computarizada para Caracterización de Yacimientos, Escuela de Ingeniería de Petróleos, Universidad Industrial de Santander, Bucaramanga, Colombia. edherote@uis.edu.co 


\section{INTRODUCCIÓN}

Teniendo en cuenta el esmerado trabajo de la industria petrolera en estimar datos petrofísicos más exactos con el fin de elaborar mejores predicciones del comportamiento de los yacimientos y así poder caracterizar y estimar reservas, surge la necesidad de mejorar e innovar cada día en la tecnología requerida para dicho estudio.

La tomografía computarizada de rayos X (CT, por sus siglas en inglés) es actualmente una técnica ampliamente usada en el estudio de las rocas, debido a la gran utilidad que presenta en varios campos. Permite la inspección de la estructura interna de la roca, identificando fracturas, heterogeneidades entre otras características que no son apreciables al ojo humano (Hunt et al., 1988). Otros trabajos como el de MacGregor et al. (1991), realizó su estudio en núcleos no consolidados con la implementación de esta tecnología. Nordtvedt et al. (1997), la usó para verificar saturaciones al interior de la roca en estado estacionario. Bergosh et al. (1985) y Honarpour et al. (1986), utilizaron esta herramienta para el análisis de sistemas de fracturas. Otras aplicaciones apoyadas en la CT para la industria de los hidrocarburos se encuentran en otros trabajos (Withjack et al., 2003; Kantzas et al., 1992). Además Siddiqui y Khamees (2004), plantea un método matemático para la determinación de algunas de las propiedades básicas de la roca, como lo son: la densidad, número atómico y la porosidad, las cuales son de gran importancia para posteriores análisis.

En la presente investigación se dan a conocer algunos de los beneficios que presenta la aplicación de la tecnología CT en la industria de los hidrocarburos para análisis petrofísicos, entre los cuales está la estimación cualitativa de la heterogeneidad a partir de la visualización de imágenes 3D de muestras tipo plug. Dada la importancia que presenta para la industria tomar en cuenta la variación de las propiedades petrofísicas (Heterogeneidad), este trabajo se enfocó en elaborar un método que nos permita estimar de manera cuantitativa la heterogeneidad de las muestras tipo plug sometidas a estudio por medio de la tomografía computarizada de rayos $\mathrm{X}(\mathrm{CT})$, basados en la diferencia de densidades de la muestra, debido a los diferentes materiales que esta presenta. La CT aprovecha la diferencia que existe en la atenuación producida por los diferentes materiales al ser expuestos a rayos $\mathrm{X}$, y genera una serie de imágenes o cortes de la muestra, que con manejo adecuado nos brindan la información necesaria para desarrollo del método. Además con la elaboración de este método se busca establecer un procedimiento estándar que permita estimar que tan representativa es una muestra de roca tipo plug a partir del cálculo de la heterogeneidad usando la tomografía, y así promover el desarrollo de posteriores pruebas, y garantizar la fiabilidad de las mismas.

Para el desarrollo de la metodología se tuvo en cuenta diferentes conceptos estadísticos generales como el de población, muestra, y unidad de estudio. Para nuestro caso la población sería el núcleo completo de la formación, la muestra sería el plug que pertenece al núcleo y la unidad de estudio sería cada corte de la muestra o imagen obtenida por el barrido tomografico,

También se tuvo en cuenta las medidas de centralización las cuales permiten establecer un valor que represente la muestra, como lo es la media la cual es el promedio de todos los valores y la moda que es el valor que más se repite en la muestra para el caso se busca el coeficiente de atenuación que sea predominante en la muestra.

Otros parámetros estadísticos que fueron la base para el cálculo de la heterogeneidad, son las medidas de dispersión, una de estas es la desviación típica que mide que tan alejados están los datos de una medida de centralización como la media o promedio y el coeficiente de variación que mide que tan significativa o que porcentaje representa la desviación típica respecto a la media o promedio.

\section{FUNCIONAMIENTO DE LA CT}

La tomografía es una técnica que se basa en obtener imágenes de cortes del cuerpo sometido a estudio, apreciando su estructura interna de manera que no afecte la integridad de la muestra. Para lograr esto, en la CT el tomógrafo emite rayos $\mathrm{X}$ moviéndose alrededor de la muestra de roca, y debido al material que atraviesen ocurrirá una pérdida de intensidad del haz de rayos- $X$ incidente, donde el haz transmitido de rayos-X es detectado por el tomógrafo mediante un anillo de detectores todo esto con el fin de realizar un escaneo completo, el cual permitirá la creación de las imágenes o cortes de la muestra. Estas imágenes muestran por medio de diferentes atenuaciones los diferentes materiales que se presentan con sus respectivas densidades. Algunos autores explican más a fondo el funcionamiento de esta tecnología y analizan algunas características significativas (Ramírez et al., 2008; Ortiz et al., 2015; Wellington y Vinegar, 1987) (FIGURA 1). 


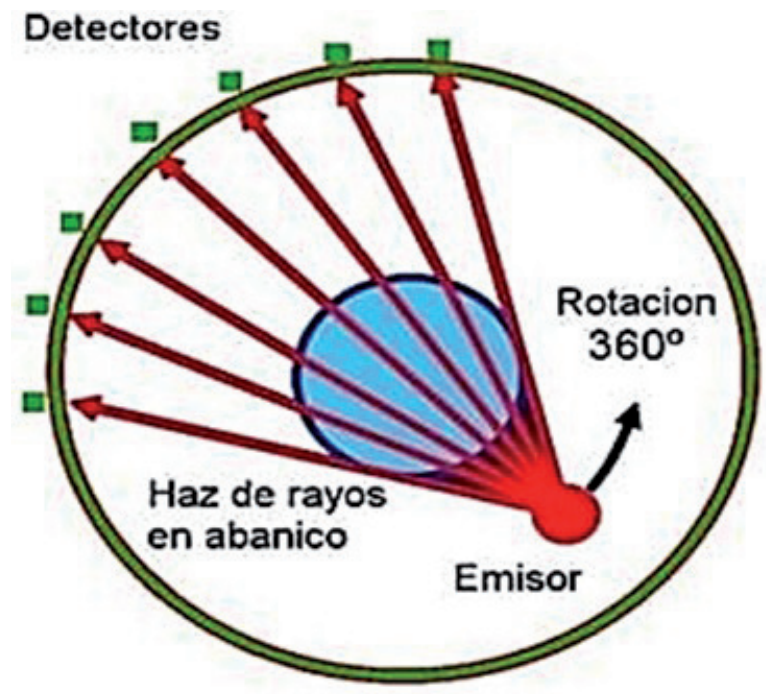

FIGURA 1. Funcionamiento básico del equipo de tomografía o tomógrafo (González-Arias, 2012).

La correlación es directa, los rayos-X transmitidos $\mathrm{y}$ que poseen menos intensidad, representan los puntos de mayor densidad y de números atómicos más altos en la muestra analizada, y se traducen en mayor atenuación. Esta condición es debida fundamentalmente a dos fenómenos, el Efecto Fotoeléctrico y el Efecto Compton, los cuales son regidos por la energía de emisión de los rayos $\mathrm{X}$, la densidad y numero atómico de los materiales expuestos (Hunt et al., 1988).

Es importante tener en cuenta que la calidad de las imágenes depende de la resolución del tomógrafo, lo que permite una mejor discretización de las imágenes, como resultado se obtienen pequeñas unidades volumétricas o Vóxel a la cual se les asigna un único valor de atenuación que llamamos coeficiente de atenuación o número CTn, el cual está directamente relacionado a la densidad del material. De acuerdo al planteamiento anterior, entre menor sean las dimensiones del vóxel, el tomógrafo presenta mayor grado de discretización o resolución, y mayor será la capacidad de detectar las posibles estructuras internas y heterogeneidades (FIGURA 2).

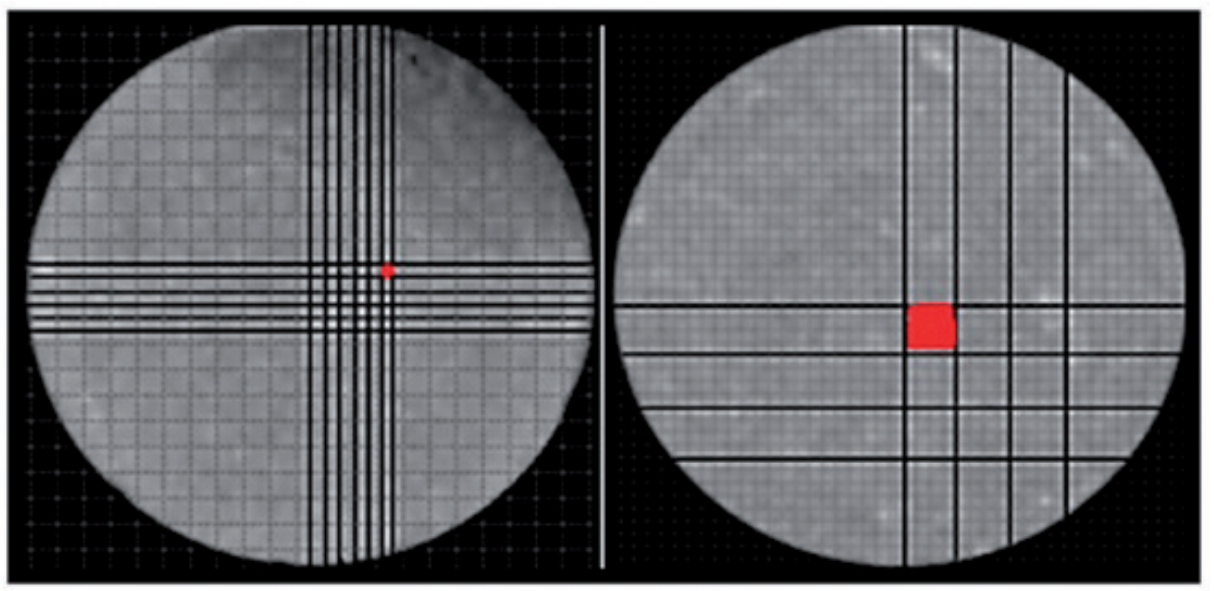

FIGURA 2. Discretización de la imagen en la cual vemos el grado de discretización mayor y menor, y en rojo la sección de la unidad de estudio Vóxel a la cual se asignamos un valor de coeficiente de atenuación.

\section{HETEROGENEIDAD}

En el trabajo de Martínez (2003) se habla de heterogeneidad como: "Todo medio es heterogéneo si cierta propiedad establecida varía en la ubicación espacial del mismo medio, en caso de ser invariante, el medio será homogéneo", teniendo en cuenta esto se puede definir la heterogeneidad como la variación de una propiedad petrofísica en específico. Las propiedades que se pueden cuantificar a partir de las imágenes CT son la densidad total y el número atómico efectivo, ya que de acuerdo a la ley de Beer-
Lambert el coeficiente de atenuación lineal depende de la composición, la densidad del material y la energía de los fotones.

La ley de Beer-Lambert trata de un método matemático el cual se usa para expresar la forma en que la materia absorbe la luz. Esta ley afirma que la totalidad de luz que irradia de determinada fuente, puede disminuir debido a tres factores:

1. Concentración: Se define como el número de materiales con capacidad de absorción del fotón en su trayectoria. 
2. Distancia del trayecto óptico: Se entiende como la distancia que el fotón debe atravesar a través de la muestra.

3. Absorbencia o coeficiente de atenuación: Las probabilidades que hay de que el fotón de una amplitud particular de onda pueda absorberse por el material.

Teniendo en cuenta esto, se afirma que la intensidad de un haz de fotones declina a medida que pasa por un medio absorbente. Esta declinación es llamada transmitancia que se define como la intensidad de la radiación transmitida, dividida entre la intensidad de la radiación incidente, esta intensidad de luz absorbida por el material, que en este caso sería la muestra, es la clave para el hallazgo de los coeficientes de atenuación.

Para analizar la variabilidad o heterogeneidad de las rocas en este proyecto sobre cada muestra sometida estudio, se tendrá en cuenta la densidad calculada por el coeficiente de atenuación y se relacionara con el cálculo de la porosidad para posteriormente hallar la heterogeneidad sobre ella, ya que la distribución y tipología de porosidad es una propiedad relevante dado que afecta directamente el almacenamiento de fluidos y lo convencional es referirnos a la heterogeneidad en función de ella, además determinarla es una de la principales aplicaciones de la tomografía.

La heterogeneidad es una de las propiedades que mejor se pueden identificar y analizar con el uso de la tomografía computarizada de rayos $\mathrm{X}$ en las diferentes muestras de roca. Su estudio es de vital importancia en el área de simulación de yacimiento ya que si se obtiene una información adecuada de la heterogeneidad, se podrá predecir mejor el comportamiento de los fluidos en yacimiento. Con esta técnica lo usual es calcular visualmente o cualitativamente la heterogeneidad, lo cual provoca cierto margen de error. Lo que se busca con este proyecto es reducir ese margen de error con un cálculo cuantitativo sencillo que nos permita darle valores objetivos a ciertos grados de heterogeneidad.

\section{DESARROLLO METODOLÓGICO}

Los datos con los cuales se desarrolla esta metodología fueron obtenidos a partir del escaneo de las muestras con un equipo GE OPTIMA 660, con el cual las muestras fueron sometidas a una energía de $140 \mathrm{kv}$ y 10 Ma considerando este nivel de energía como alto.

La diferencia entre los coeficientes de atenuación de cada material debido a sus diferentes densidades es en lo que se basa esta tecnología y este método. A partir de esto se inicia con la recopilación de los datos, como son las imágenes del barrido tomográfico para darles un manejo adecuado con la ayuda de software de visualización, y mediante el uso de una hoja de cálculo (Excel) se halla la porosidad basada en la ecuación 1 descrita en los trabajos propuestos por Kantzas et al. (1992), y por último se emplean algunos conceptos estadísticos a los valores obtenidos con los cuales se determina la heterogeneidad de las muestras.

$$
\begin{gathered}
\emptyset=\frac{\rho_{R}-\rho_{B c}}{\rho_{R}-\rho_{F}} \\
\text { Densidad de Grano }\left(\rho_{R}\right)>\text { Densidad Total }\left(\rho_{B}\right)>\text { Densidad del Fluido }\left(\rho_{F}\right) \\
\text { Porosidad }(\emptyset)
\end{gathered}
$$

\section{RECOPILACIÓN DE LAINFORMACIÓN DE LAS MUESTRAS}

Para el desarrollo de esta metodología se tuvieron en cuenta 9 muestras tipo plug (TABLA 1), contando con información indispensable de cada una de las muestras. Por parte del barrido tomográfico se obtuvieron las imágenes de los cortes y el registro del escaneo de densidad para cada muestra; y por parte de algunos análisis realizados anteriormente a las muestras, se obtuvieron la porosidad promedio medida por el método de Boyle (Pérez et al., 2017) la densidad el fluido, que en este caso es la del aire $0,0013 \mathrm{~g} / \mathrm{cc}$, ya que las muestras se analizan en un estado estático, la densidad de grano para algunas muestras y algunos análisis cualitativos realizados. 
TABLA 1. Muestras sometidas a estudio.

\begin{tabular}{cll}
\hline \multicolumn{3}{c}{ Muestras } \\
\hline N. & \multicolumn{1}{c}{ Nombre } & \multicolumn{1}{c}{ Tipo } \\
\hline 1 & B-TC-PET-06 & Berea \\
2 & ALT1C & Sintética \\
3 & CD3 & Sintética \\
4 & D65B & Sintética \\
5 & RP-ALT2 & Sintética \\
6 & RPCD1 & Sintética \\
7 & LM3-1-2 & Nativa Mugrosa \\
8 & LM4-1-1 & Nativa Mugrosa \\
9 & LM4-2-5 & Nativa Mugrosa \\
\hline
\end{tabular}

\section{Cálculo de los coeficientes de atenuación CTn}

Después se procede a calcular los promedios de los coeficientes de atenuación para cada corte, y promediarlos para obtener el promedio total de número CTn para cada muestra. Esto lo realizamos por medio de la implementación del software de visualización ImageJ, el cual permite manipular los coeficientes de atenuación de diferentes formas. Una forma de manejo de los coeficientes de atenuación es en forma de matrices, pero para el método es necesitamos obtener el promedio de los números CTn de cada corte y el promedio total de los números CTn para toda la muestra. Para esto recurrimos a la facilidad de manejo de los datos que permiten las herramientas del software, donde se puede copiar esta matriz y llevarla a una hoja de cálculo y realizar el promedio para cada corte. Este proceso se vuelve molesto y extenuante, debido a la cantidad de cortes que puede tener una muestra (de 100 a 300 imágenes aproximadamente), pero gracias a la variedad de menús y herramientas que presenta el software para el análisis de los datos, se encontró una forma más práctica y sencilla de sacar el promedio de los números CTn de cada corte de la muestra. Esto se realizó a partir de una gráfica producida en ImageJ del perfil de coeficientes de atenuación a lo largo del barrido tomográfico, el cual proporciona el coeficiente de atenuación promedio para cada corte realizado a la muestra (FIGURA 3).

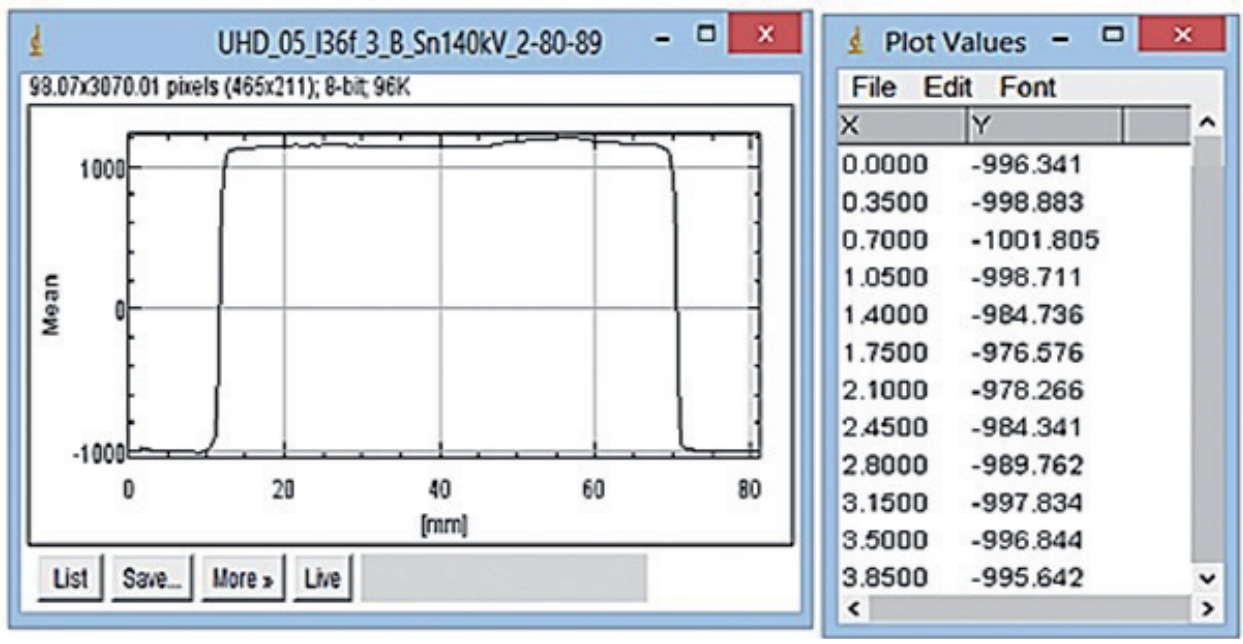

FIGURA 3. Distribución de los coeficientes de atención a lo largo de la muestra.

Visualización con el software ImageJ de la gráfica realizada de perfil de coeficientes y su tabla de valores, donde el eje X representa el largo de toda la muestra en milímetros y el eje Y son los coeficientes de atenuación o números $\mathrm{CTn}$ promedios de cada corte. También se puede apreciar los coeficientes que no representan la muestra de roca al final e inicio del perfil, debido a que el barrido tomográfico inicia un poco antes del inicio de la muestra y así mismo termina después de escanear completamente.
Los valores obtenidos en el perfil de coeficientes son llevados Excel para descartar aquellos cortes que no sirven, y así promediar los datos que si pertenecen a la muestra y hallar el coeficiente de atenuación promedio para toda la muestra, ya que este dato es necesario para el desarrollo del siguiente paso. Una vez se haya completado la fase de obtener los coeficientes de atenuación promedio, se procede a determina la densidad total promedio de cada muestra. Se debe resaltar que la densidad total promedio de cada muestra 
debe tenerse o debe poderse calcular para el progreso de la metodología. Para nuestro caso se obtuvo gracias al registro del escaneo de densidad obtenido en el barrido tomográfico (FIGURA 4), este registro se lleva a Excel y se calcula la densidad total promedio de toda la muestra.

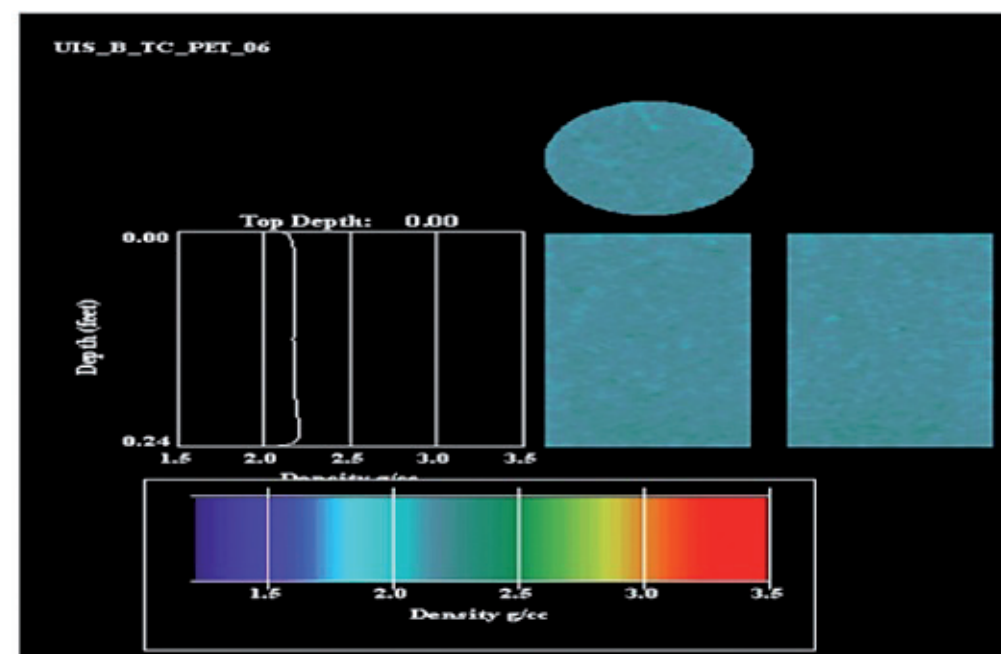

FIGURA 4. Registro del escaneo de densidad obtenido del barrido tomográfico.

\section{Calibración de la densidad}

La calibración de la densidad consiste en una gráfica que permite obtener cualquier densidad a partir de un número CTn (Kantzas et al., 1992). Donde una vez obtenida la densidad total y el coeficiente de atenuación promedio de cada muestra se procede a crear la gráfica de calibración de la densidad, donde el eje Y manejara la densidad total y eje $\mathrm{X}$ los números CTn (TABLA 2).

TABLA 2. Muestras estudiadas con su respectiva Densidad total y Numero CTn promedios.

\begin{tabular}{llcc}
\hline N. & \multicolumn{1}{c}{ Muestras } & $\begin{array}{c}\text { Densidad total promedio } \\
\mathbf{p B}\left(\mathbf{g} / \mathbf{c m}^{3}\right)\end{array}$ & CTn promedio \\
\hline 1 & B-TC-PET-06 Berea & 2,1734 & 1119,7105 \\
2 & ALT1C Sintética & 2,1836 & 1091,7187 \\
3 & CD3 Sintética & 2,0421 & 964,4454 \\
4 & D65B Sintética & 2,0408 & 948,8695 \\
5 & RP-ALT2 Sintética & 2,0794 & 992,8719 \\
6 & RPCD1 Sintética & 2,1111 & 1028,3286 \\
7 & LM3-1-2 Nativa Mugrosa & 2,1806 & 1119,4863 \\
8 & LM4-1-1 Nativa Mugrosa & 2,2201 & 1143,9231 \\
9 & LM4-2-5 Nativa Mugrosa & 2,2297 & 1152,4431 \\
\hline
\end{tabular}


En la TABLA 2 se aprecian los valores para cada muestra, se escogieron 6 de las 9 muestras resaltadas, para la realización de la gráfica, repartidas teniendo en cuenta su tipo (1 bérea, 3 sintéticas, 2 nativas), esto con el fin de observar si la gráfica sirve para muestras similares que presenten las mismas dimensiones y su escaneo sea con la misma resolución del tomógrafo.

$$
\rho_{B}=\alpha C T_{n}+\beta
$$

Realizamos la curva de calibración de densidad con el fin de obtener una ecuación con la cual podamos calcular la densidad para cualquier valor de número CTn, para esto se traza la línea de tendencia y con base en el trabajo de Kantzas et al. (1992) hallamos la ecuación 2 para la cual alfa que es la pendiente, se obtuvo un valor de 0,0009 , y beta que es el punto de corte con el eje Y, un valor de 1,1808 (FIGURA 5).

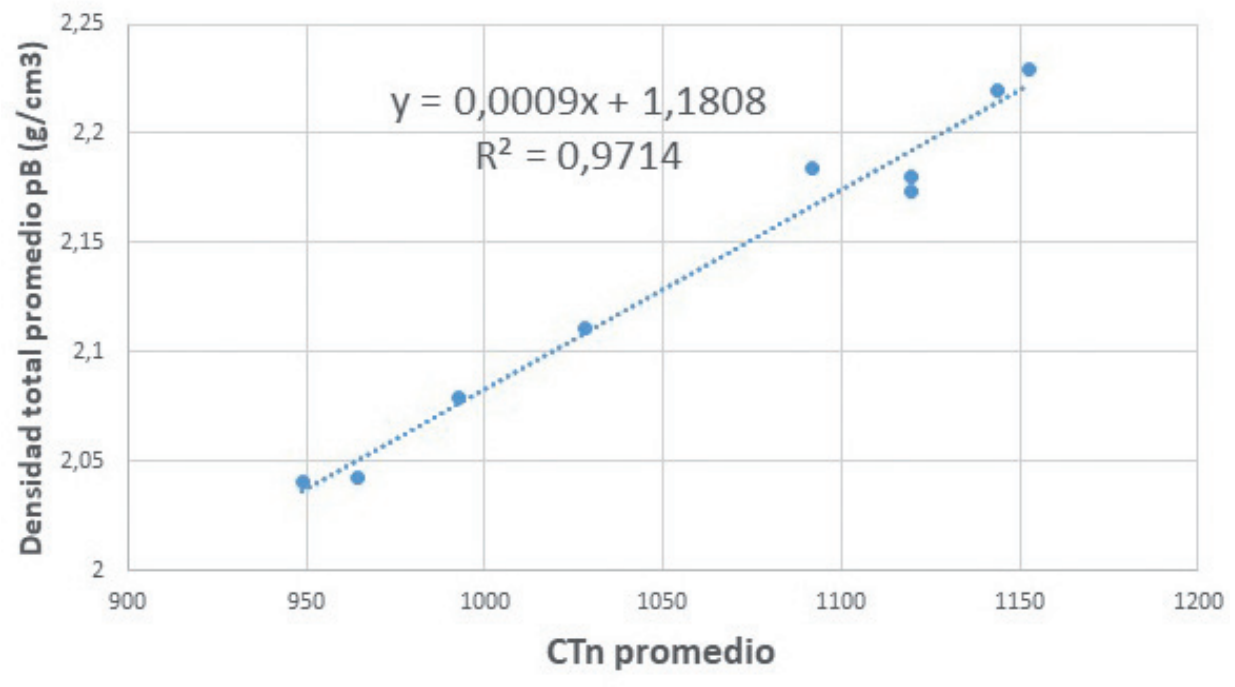

FIGURA 5. Gráfica de calibración de la densidad según la ecuación 2.

$$
\rho_{B c}=\left(0,0009 * C T_{n}\right)+1,808
$$

Una vez aclarados los valores que corresponden a la pendiente y el punto de corte de la línea de tendencia en la gráfica se calculan las densidades totales promedio para cada uno de los cortes de las muestras. Este cálculo se hace por medio de la ecuación de la línea de tendencia de la gráfica anterior, y como ya se tienen los coeficientes de atenuación promedios para cada corte extraídos del perfil realizado en el software ImageJ, procedemos a calcular las densidades totales para cada corte con la ecuación 3 , hallada con la gráfica y que se muestra en función de los números CTn.

\section{Porosidad promedio para cada corte}

Con la metodología desarrollada, se busca definir la heterogeneidad en muestras de roca tipo plug, basada en los valores de la porosidad, ya que al momento de caracterizar un yacimiento como homogéneo o heterogéneo, generalmente se hace bajo la influencia de la porosidad, es decir, se dice que un yacimiento es homogéneo cuando no presenta mayores variaciones en la porosidad, y de igual forma se dice que un yacimiento es heterogéneo si presenta grandes variaciones en su porosidad. Por este motivo se decidió realizar el estudio de la heterogeneidad sobre la propiedad de la porosidad, además que hallarla es una de las principales aplicaciones de la CT. Para esto se necesitó de la determinación de la misma, a partir de las densidades totales de cada corte o imagen de la muestra, y realizar el análisis de variabilidad o heterogeneidad que se presenta.

$$
\begin{gathered}
\rho_{B c}=(1-\emptyset) \rho_{R}+\emptyset \rho_{F} \\
\varnothing=\frac{\rho_{R}-\rho_{B c}}{\rho_{R}-\rho_{F}}
\end{gathered}
$$

\section{Densidad de Grano $\left(\rho_{R}\right)>$ Densidad Total $\left(\rho_{B}\right)>$ Densidad del Fluido $\left(\rho_{F}\right)$}


Esto se realizó usando ecuación 4 basada en los trabajos de Kantzas et al. (1992), de la cual despejamos la porosidad y obtenemos la ecuación 5 (Kantzas et al., 1992), en función de la densidad total de cada corte, la densidad de grano de cada muestra y la densidad del fluido que en este caso es la del aire $(0,0013 \mathrm{~g} /$ cc). Dichas ecuaciones provienen de información de la Universidad de Calgary. Es importante tener en cuenta que en algunas muestras no tenemos la densidad de grano y que esta la podemos calcular a partir de la misma ecuación utilizando la porosidad promedio de toda la muestra, determinada en el laboratorio por el método de Boyle (Pérez et al., 2017) la densidad total hallada anteriormente para la gráfica y la densidad del fluido que no se altera.

\section{Aplicación de conceptos estadísticos}

$$
\begin{gathered}
\text { Media o Promedio }=\frac{\sum_{i=1}^{N} X_{i}}{N} \\
\text { Desviación } T=\sigma=\sqrt{\frac{\sum_{i=1}^{N}\left(X_{i}-\bar{X}\right)^{2}}{N}} \\
\text { Coeficiente de Variación }=C_{v}=\frac{\sigma}{\bar{X}}
\end{gathered}
$$

Se tuvo en cuenta diferentes conceptos estadísticos (Descartes. Unidad Didáctica). Conceptos generales como el de población, muestra, y unidad de estudio. Para nuestro caso la población seria el núcleo completo de la formación, la muestra sería el plug que pertenece al núcleo y la unidad de estudio seria cada corte de la muestra. De igual forma fue necesario el uso de parámetros de centralización los cuales permiten establecer un valor que represente la muestra, como lo es la Media, que es el promedio de todos los valores y la Moda, que es el valor que más se repite en la muestra. Otros parámetros estadísticos que fueron la base para el cálculo de la heterogeneidad, son las medidas de dispersión, una de estas es la desviación típica $(\sigma)$ que mide que tan alejados están los datos de una medida de centralización como la media o promedio, y el coeficiente de variación que mide que tan significativa o que porcentaje representa la desviación típica respecto a la media o promedio. Las ecuaciones 6,7 y 8 muestran los conceptos estadísticos más significativos con su respectiva formula, donde $X_{i}$ representa cada coeficiente representado individualmente, $\mathrm{N}$ la cantidad total de coeficientes presentes en cada corte o imagen de la muestra y $\bar{X}$ representa la media o promedio de los coeficientes.

Se debe tener en cuenta que entre menor sean los valores de desviación típica y de coeficiente de variación, menor será la variación de los datos, es decir, que menor será la heterogeneidad de la muestra (TABLA 3).

TABLA 3. Aplicación de los conceptos estadísticos Media, Desviación Típica y Coeficiente de Variación.

\begin{tabular}{llccccc}
\hline \multicolumn{1}{c}{ Muestra } & $\begin{array}{c}\text { Media de } \\
\text { porosidad }\end{array}$ & $\begin{array}{c}\text { Desviación } \\
\text { típica }\end{array}$ & $\begin{array}{c}\text { Desviación } \\
\text { típica (Barras) }\end{array}$ & $\begin{array}{c}\text { Coeficiente de } \\
\text { variación }\end{array}$ & $\begin{array}{c}\text { Coeficiente de } \\
\text { variación }\end{array}$ \\
\hline B-TC-PET-06 Berea & 0,1843384777 & 0,00322867024 & 0,003228670 & 0,017514901 & 0,017514901 \\
ALT1C Sintética & 0,140070807 & 0,01449178718 & 0,014491787 & 0,103460439 & 0,103460439 \\
CD3 Sintética & 0,177304523 & 0,00520287565 & 0,005202876 & 0,029344292 & 0,029344292 \\
D65B Sintética & 0,217327120 & 0,00627826109 & $\mathbf{0 , 0 0 6 2 7 8 2 6 1}$ & 0,02888853 & 0,02888853 \\
RP-ALT2 Sintética & 0,168002936 & 0,01319002416 & $\mathbf{0 , 0 1 3 1 9 0 0 2 4}$ & 0,078510676 & 0,078510676 \\
RPCD1 Sintética & 0,154935760 & 0,00496170137 & $\mathbf{0 , 0 0 4 9 6 1 7 0 1}$ & 0,032024249 & 0,032024249 \\
LM3-1-2 Nativa Mugrosa & 0,233788417 & 0,003469488821 & $\mathbf{0 , 0 0 3 4 6 9 4 8 8}$ & 0,014840291 & 0,014840291 \\
LM4-1-1 Nativa Mugrosa & 0,244740864 & 0,00727652545 & $\mathbf{0 , 0 0 7 2 7 6 5 2 5}$ & 0,029731551 & 0,029731551 \\
LM4-2-5 Nativa Mugrosa & 0,216028331 & 0,00674393682 & $\mathbf{0 , 0 0 6 7 4 3 9 3 7}$ & 0,031217835 & 0,031217835 \\
\hline
\end{tabular}


En la TABLA 3 se observan los resultados obtenidos con las ecuaciones 6,7 y 8 para los diferentes conceptos estadísticos y se muestran en verde las muestras con menor heterogeneidad y en rojo las más heterogéneas. Así mismo se realizó con barras para mejor apreciación de los resultados.
A continuación se presenta el organigrama de la metodología (FIGURA 6) que se realizó en este trabajo para las muestras sometidas al estudio.

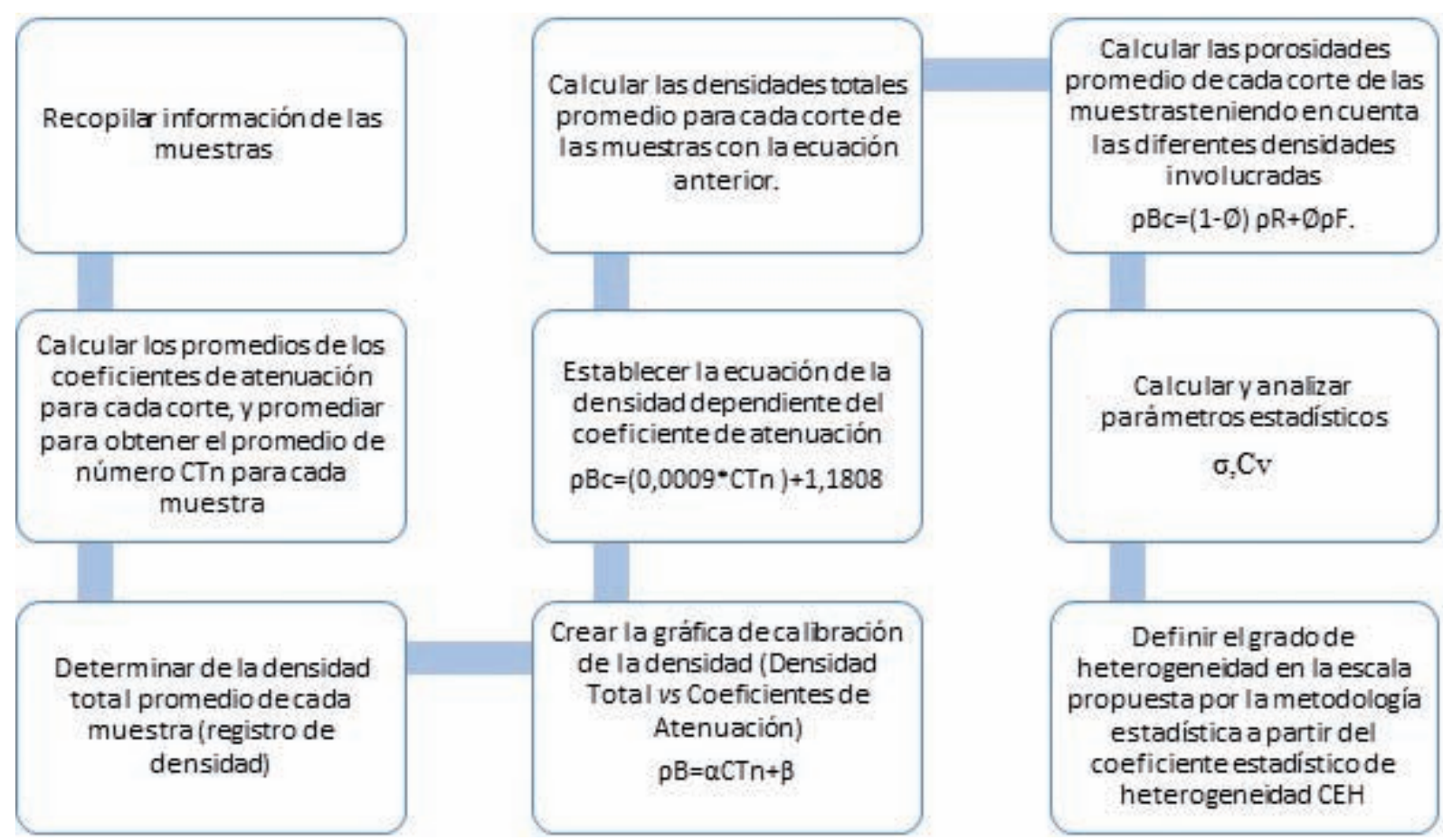

FIGURA 6. Organigramas de la metodología desarrollada.

\section{PARÁMETROS EXPERIMENTALES Y RESULTADOS}

\section{Escala de clasificación de la heterogeneidad}

$$
C E H=\sigma+C_{V}
$$

Gracias al análisis estadístico se pudo evidenciar que al ordenar las muestras según la desviación típica y coeficiente de variación, estas no mantenían el mismo orden. A partir de esto se estableció un nuevo parámetro estadístico al cual llamamos Coeficiente Estadístico de Heterogeneidad (CEH), que brinda una normalización o un punto de equilibrio entre estos dos parámetros de dispersión. Por ejemplo la muestra RPCD1 Sintética ocupa el tercer lugar en menor desviación típica, el séptimo en coeficiente de variación y en el CEH el quinto, dando un equilibrio entre estos dos parámetros (TABLA 4). Con este nuevo parámetro lo identificaremos con las letras $\mathrm{CEH}$ y teniendo en cuenta diferentes operaciones se estableció una formula sencilla con el fin de establecer este punto de equilibrio, la cual es la suma de la desviación típica $(\sigma)$ y el coeficiente de variación como se observa en la ecuación 9.

A partir de este nuevo parámetro $\mathrm{CEH}$, se estableció una escala de clasificación de la heterogeneidad para muestras de roca tipo plug (TABLA 5), que cuenta con 4 diferentes clasificaciones cualitativas de heterogeneidad, con grados de heterogeneidad en un rango de 1 a 10 según la escala cuantitativa planteada, la cual permite determinar qué tan representativa es la muestra del yacimiento, y así poder sugerir su uso para posteriores pruebas. Además de una escala de colores que manejamos a lo largo de la investigación. 
TABLA 4. Resultados ordenados de las muestras según el Coeficiente de Variación, Desviación Típica y Coeficientes estadístico de heterogeneidad (CEH).

\begin{tabular}{ll}
\hline & \multicolumn{1}{c}{ Orden de las muestras según el coeficiente de variación } \\
\hline LM3-1-2 Nativa Mugrosa & 0,014840291 \\
B-TC-PET-06 Berea & 0,017514901 \\
D65B Sintética & 0,02888853 \\
CD3 Sintética & 0,029344292 \\
LM4-1-1 Nativa Mugrosa & 0,029731551 \\
LM4-2-5 Nativa Mugrosa & 0,031217835 \\
RPCD1 Sintética & 0,032024249 \\
RP-ALT2 Sintética & 0,078510676 \\
ALT1C Sintética & 0,103460439 \\
\hline
\end{tabular}

\begin{tabular}{ll}
\hline \multicolumn{1}{c}{ Orden de las muestras según la desviación típica } \\
\hline B-TC-PET-06 Berea & 0,00322867 \\
LM3-1-2 Nativa Mugrosa & 0,003469488 \\
RPCD1 Sintética & 0,004961701 \\
CD3 Sintética & 0,005202876 \\
D65B Sintética & 0,006278261 \\
LM4-2-5 Nativa Mugrosa & 0,006743937 \\
LM4-1-1 Nativa Mugrosa & 0,007276525 \\
RP-ALT2 Sintética & 0,013190024 \\
ALT1C Sintética & 0,014491787 \\
\hline
\end{tabular}

\begin{tabular}{lc}
\hline \multicolumn{1}{c}{ Orden de las muestras según el coeficiente estadístico de heterogeneidad } \\
\hline LM3-1-2 Nativa Mugrosa & 0,018309779 \\
B-TC-PET-06 Berea & 0,020743572 \\
CD3 Sintética & 0,034547167 \\
D65B Sintética & 0,035166791 \\
RPCD1 Sintética & 0,03698595 \\
LM4-1-1 Nativa Mugrosa & 0,037008076 \\
LM4-2-5 Nativa Mugrosa & 0,037961772 \\
RP-ALT2 Sintética & 0,091700701 \\
ALT1C Sintética & 0,117952226 \\
\hline
\end{tabular}

TABLA 5. Escala de clasificación de la heterogeneidad para muestras de roca tipo plug.

\begin{tabular}{ccc}
\hline $\begin{array}{c}\text { Intervalos del coeficiente estadístico de } \\
\text { heterogeneidad }\end{array}$ & $\begin{array}{c}\text { Grados de } \\
\text { heterogeneidad }\end{array}$ & $\begin{array}{c}\text { Clasificación cualitativa de } \\
\text { heterogeneidad }\end{array}$ \\
\hline $\begin{array}{c}\mathrm{CEH}<2,0 \% \\
2.0 \%<\mathrm{CEH}<2,6 \%\end{array}$ & 1 & Homogénea \\
\hline $2.6 \%<\mathrm{CEH}<3,2 \%$ & 2 & Baja Heterogeneidad \\
$3.2 \%<\mathrm{CEH}<3,6 \%$ & 3 & Mediana Heterogeneidad \\
\hline $3.6 \%<\mathrm{CEH}<4,0 \%$ & 4 & Heterogénea \\
$4.0 \%<\mathrm{CEH}<5,0 \%$ & 5 & \\
$5.0 \%<\mathrm{CEH}<6,0 \%$ & 6 & 7 \\
\hline $6.0 \%<\mathrm{CEH}<8,0 \%$ & 8 & \\
$8.0 \%<\mathrm{CEH}<10 \%$ & 9 & 10 \\
$10 \%<\mathrm{CEH}$ & &
\end{tabular}




\section{DISCUSIÓN DE LOS RESULTADOS}

\section{Software de visualización}

Luego de que las proyecciones radiográficas individuales han sido compiladas en un archivo de datos, producto del barrido tomográfico, pueden cargarse en un ambiente de visualización para someterse a un análisis detallado. Se necesita de mucha información para hacer un análisis eficaz de las imágenes obtenidas mediante la tomografía computarizada $\mathrm{CT}$, por tal razón se hace necesario el uso de herramientas de visualización o software de visualización. Estas herramientas permiten manejar fácilmente las imágenes obtenidas mediante la tomografía y hacer un análisis significativo sobre ellas. Para el desarrollo de la metodología y en el análisis de la heterogeneidad en rocas se usaron dos software de libre distribución: El Mango permite realizar un análisis cualitativo de las muestras a partir de histogramas gracias a su facilidad de trabajo y el ImageJ permite el manejo de los coeficientes de atenuación y realizar un análisis detallado de los mismos, donde fue necesario recurrir al manual propuesto por Sánchez (2015) para el uso del software de visualización ImageJ.

\section{Coeficientes de atenuación para cada corte}

El análisis de las imágenes obtenidas en el estudio tomográfico completo de la muestra es de vital cuidado, ya que de esta depende la calidad de los datos que se someterán al análisis estadístico propuesto. Partiendo de un conjunto de imágenes correspondientes a los cortes generados por el barrido tomográfico que se realiza a la muestra analizada, se busca generar un volumen en 3D a partir del uso del software de visualización y adicionalmente extraer los valores numéricos de los coeficientes de atenuación para dar un manejo estadístico de acuerdo al propósito del estudio. Es importante señalar algunas condiciones que se presentan al momento de dar uso a las imágenes obtenidas mediante tomografía.

Una de las condiciones que se presentan es el exceso de imágenes que no corresponden a la muestra, esta condición se presenta debido a que al momento de empezar el barrido tomográfico, los rayos $\mathrm{X}$ emitidos por el tomógrafo no entran en contacto inmediato con la superficie de la muestra tipo plug, sino atraviesan una región vacía que es registrada por los detectores, y de la cual se obtendrán una serie de imágenes que no deben ser tenidas en cuenta al momento de procesar los datos, ya que generaran inconsistencias o errores en el método estadístico. Esto se presenta al inicio y al final del barrido tomográfico, y por lo tanto estas imágenes deben ser descartadas ya que no aportan información valiosa o real de la muestra (FIGURA 7).
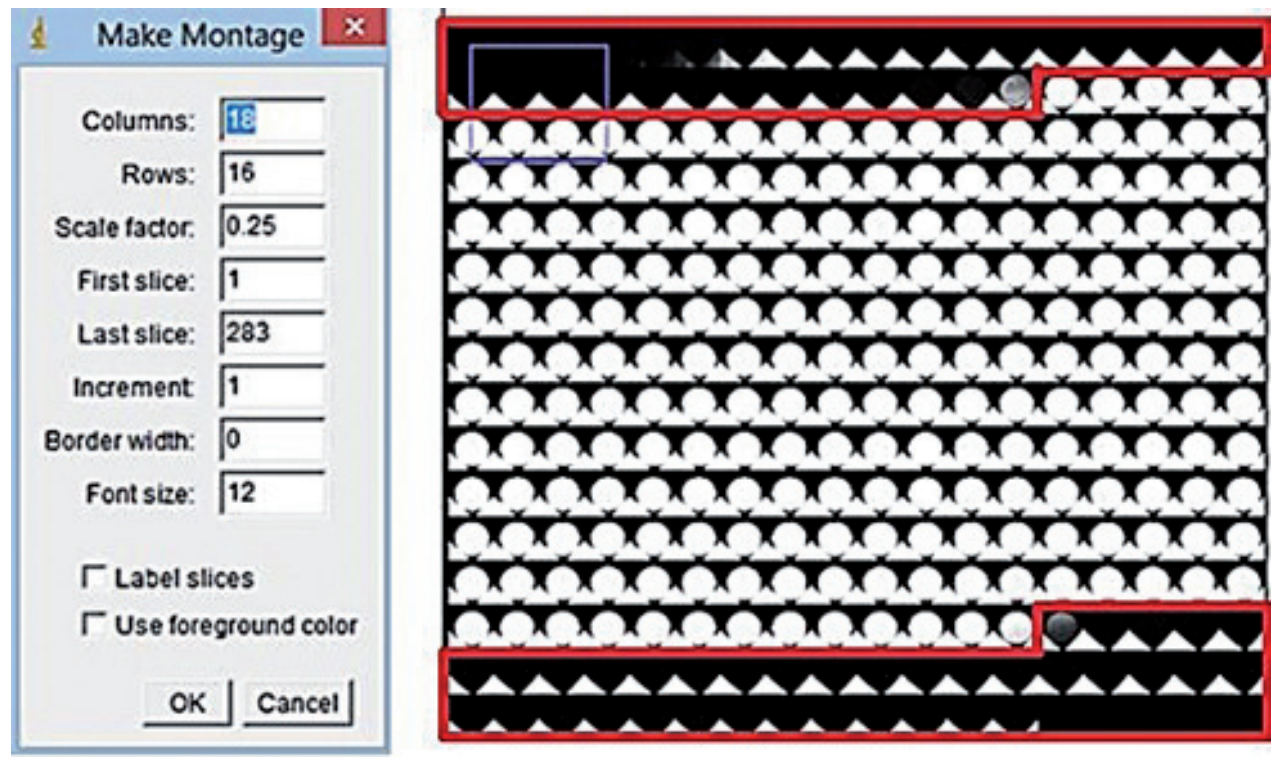

FIGURA 7. Visualización de las imágenes seleccionadas en rojo y que deben ser descartadas y que por medio del software de visualización ImageJ son fáciles de apreciar en una serie de todos los cortes realizados. 
Otra de las condiciones que se nos presenta es la selección del área en específico que se va estudiar, ya que no se debe tener en cuenta los coeficientes de atenuación que no pertenecen a la muestra (FIGURA 8).

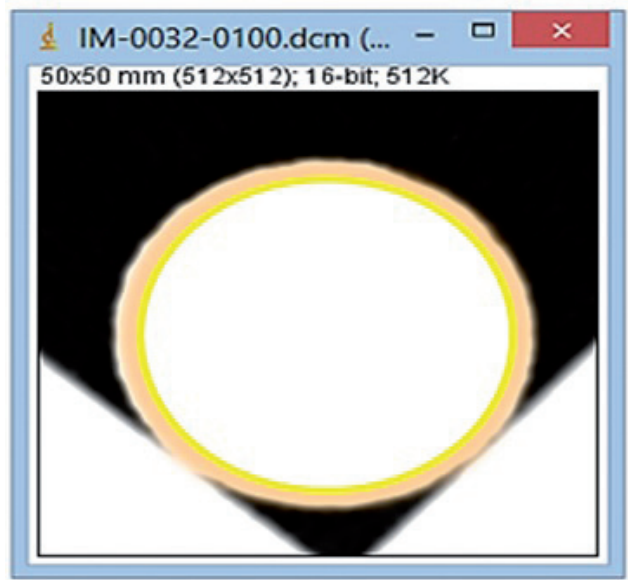

FIGURA 8. Visualización con el software ImageJ de la selección del área de la muestra tipo plug donde se usa una de las herramientas de selección de forma circular y tomamos solo el área de la muestra tipo plug con el fin de que no tenga en cuenta datos que no pertenezcan a la misma.

Teniendo en cuenta los pasos desarrollados de la metodología establecida y luego de descartar los datos que no son significativos de la muestra se obtuvieron los siguientes resultados. Los parámetros estadísticos Media, Desviación Típica y Coeficiente de Variación, para cada una de las muestras. Además del nuevo parámetro CEH y la respectiva utilización de la escala de clasificación planteada. Las que se encuentran en color verde son las muestras que presentan menor valor en estos parámetros y por tanto menos heterogéneas, para las de color rojo ocurre lo contario. Teniendo en cuenta esto, las muestras más Homogénea son la 1. B-TC-PET-06 Bérea y la 7. LM3-1-2 Nativa, y las más heterogéneas son la 2. ALT1C Sintética y la 5. RPALT2 Sintética (TABLA 6).

Los resultados obtenidos por el cálculo del coeficiente estadístico de heterogeneidad mostraron su punto de equilibrio entre los dos parámetros anteriores, y continuo dando los mismo resultados sobre las dos muestras más heterogéneas y las más homogéneas. Esta clasificación es acorde con los análisis cualitativos de cada una de las muestras, recopilados de la información que se suministró. Para terminar de garantizar la fiabilidad de los resultados por el método establecido, se crearon algunos gráficos que nos ayudaron al análisis de las muestras y verificar los resultados obtenidos.

TABLA 6. Resultados obtenidos con la aplicación de la metodología.

\begin{tabular}{|c|c|c|c|c|c|c|}
\hline $\mathbf{N}$ & Muestras & $\begin{array}{l}\text { Media de } \\
\text { Porosidad }\end{array}$ & $\begin{array}{l}\text { Desviación } \\
\text { Típica }\end{array}$ & $\begin{array}{l}\text { Coeficiente de } \\
\text { Variación }\end{array}$ & $\begin{array}{c}\text { Coeficiente } \\
\text { estadístico de } \\
\text { heterogeneidad }\end{array}$ & $\begin{array}{c}\text { Escala de clasificación de } \\
\text { heterogeneidad }\end{array}$ \\
\hline 1 & B-TC-PET-06 Berea & 0,1866 & 0,0032 & 0,0175 & 0,02070 & Homogénea -Grado 2 \\
\hline 2 & ALT1C Sintética & 0,1361 & 0,0145 & 0,1035 & 0,11800 & Heterogénea -Grado 10 \\
\hline 3 & CD3 Sintética & 0,1773 & 0,0052 & 0,0293 & 0,03450 & Baja Heterogénea -Grado 4 \\
\hline 4 & D65B Sintética & 0,2173 & 0,0063 & 0,0289 & 0,03520 & Baja Heterogénea -Grado 4 \\
\hline 5 & RP-ALT2 Sintética & 0,1680 & 0,0132 & 0,0785 & 0,09170 & Homogénea -Grado 9 \\
\hline 6 & RPCD1 Sintética & 0,1549 & 0,005 & 0,0320 & 0,03700 & Mediana Heterogénea -Grado 5 \\
\hline 7 & LM3-1-2 Nativa Mugrosa & 0,2338 & 0,0035 & 0,0148 & 0,01830 & Homogénea -Grado 1 \\
\hline 8 & LM4-1-1 Nativa Mugrosa & 0,2447 & 0,0073 & 0,0297 & 0,03700 & Mediana Heterogénea-Grado 5 \\
\hline 9 & LM4-2-5 Nativa Mugrosa & 0,2158 & 0,0067 & 0,0312 & 0,03800 & Mediana Heterogénea -Grado 5 \\
\hline
\end{tabular}

Una de ellas son los perfiles de porosidad para cada una de las muestras elaborados en hojas de cálculo. Esta grafica muestra la variación de la porosidad a lo largo de toda la muestra. Se manejó el mismo rango y proporción de los ejes para todos los perfiles de porosidad, para evidenciar de mejor manera la diferencia entre las muestras homogéneas y heterogéneas (FIGURA 9). 

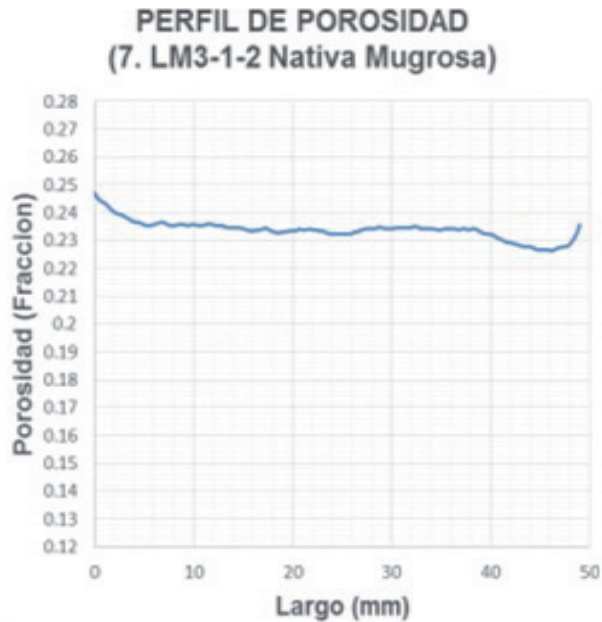

Muestra homogénea (A)
PERFIL DE POROSIDAD

(2. ALT1C Sintetica)

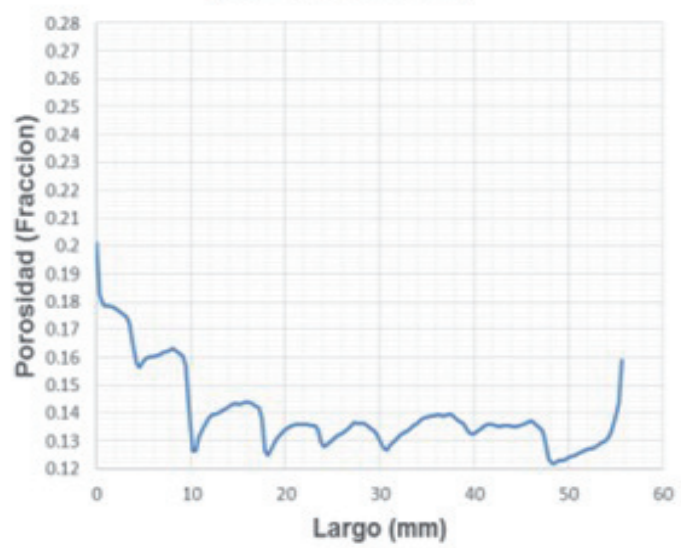

Muestra heterogénea (B)

FIGURA 9. Perfil de porosidad de la muestra 7 muestra homogénea A, y la muestra $\mathbf{B}$ que es heterogénea, donde se nota la variación de porosidad a lo largo de la muestra 2. ALT1C Sintética.

Por medio las hojas de cálculo en Excel, también se generaron gráficos de histogramas de barras, para los cuales se definieron diferentes intervalos sobre los datos de porosidad que tiene cada muestra pero teniendo en cuenta que todos los intervalos tendrán la misma amplitud de 0,005 de porosidad, este intervalo se ha definido por visualización de las gráficas ya que este facilita que se aprecien todos los datos de las diferentes muestras, con el fin de apreciar las diferencias para muestras homogéneas de las heterogéneas (FIGURA 10).

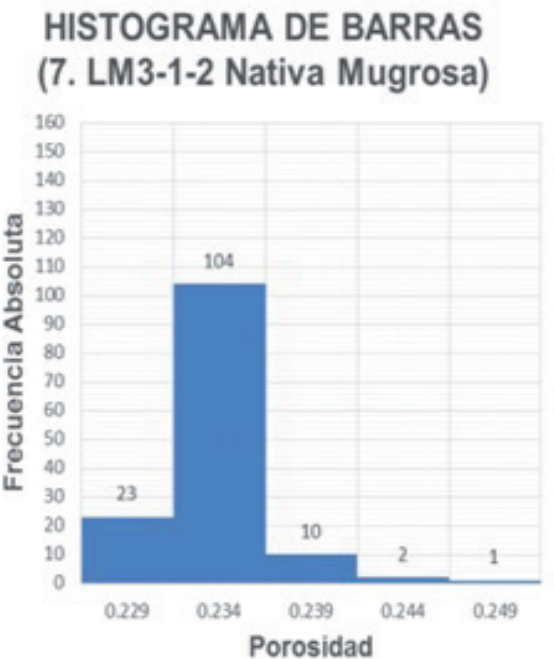

Muestra homogénea (A)

\section{HISTOGRAMA DE BARRAS (2. ALT1C Sintetica)}

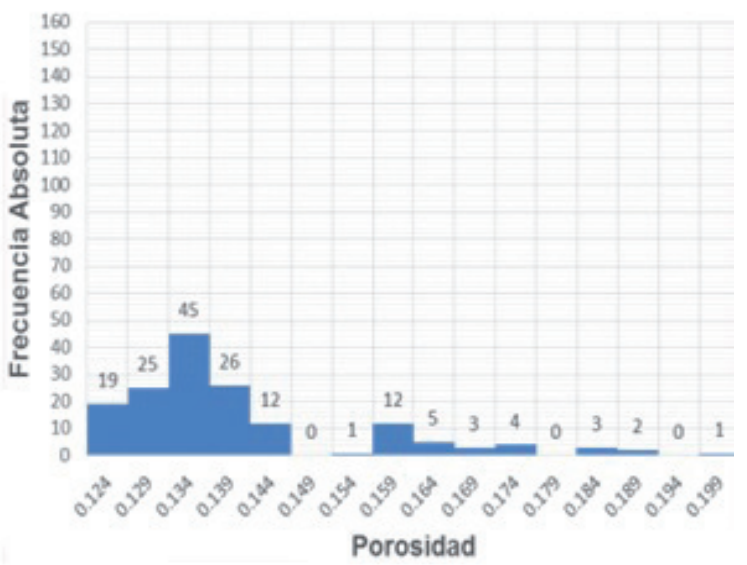

Muestra heterogénea (B)

FIGURA 10. Histogramas de barras de la muestra 7 muestra homogénea A, y la muestra $\mathbf{B}$ que es heterogénea, se nota la variación de porosidad en la muestra 2. ALT1C Sintética por tener muchos intervalos del eje X y así mismo los datos están muy repartidos en cada uno de esos intervalos, en cambio la muestra homogénea tiene pocos intervalos y tiene un alto porcentaje de datos en un solo intervalo. 


$$
\% \text { Error }=\frac{\mid V \exp -V \text { teo } \mid}{V \text { teo }} * 100
$$

Se realiza un análisis adicional con el fin de garantizar la fiabilidad de los resultados fue el cálculo del porcentaje de error entre la porosidad medida en laboratorio por el método de Boyle (Pérez et al., 2017) que tomaremos como la teórica, y la hallada por el promedio de todos los cortes de cada muestra que será la experimental. Para esto aplicamos la ecuación 10 y obtenemos los resultados de los porcentajes de error para todas las muestras (TABLA 7).

TABLA 7. Porcentaje de error entre los datos de porosidad, los cuales son bajos y garantizan la fiabilidad del método.

\begin{tabular}{llccc}
\hline N. & \multicolumn{1}{c}{ Muestras } & $\begin{array}{c}\text { Porosidad de laboratorio } \\
\text { (Boyle) }\end{array}$ & $\begin{array}{c}\text { Porosidad promedio o } \\
\text { media }\end{array}$ & $\begin{array}{c}\text { \% Error de } \\
\text { porosidad }\end{array}$ \\
\hline 1 & B-TC-PET-06 Berea & 0,1900 & 0,1866 & 1,7895 \\
2 & ALT1C Sintética & 0,1320 & 0,1361 & 3,1061 \\
3 & CD3 Sintética & 0,1800 & 0,1773 & 1,4975 \\
4 & D65B Sintética & 0,2150 & 0,2173 & 1,0824 \\
5 & RP-ALT2 Sintética & 0,1660 & 0,1680 & 1,2066 \\
6 & RPCD1 Sintética & 0,1530 & 0,1549 & 1,2652 \\
7 & LM3-1-2 Nativa Mugrosa & 0,2365 & 0,2338 & 1,1465 \\
8 & LM4-1-1 Nativa Mugrosa & 0,2414 & 0,2447 & 1,3840 \\
9 & LM4-2-5 Nativa Mugrosa & 0,2119 & 0,2158 & 1,8405 \\
\hline
\end{tabular}

$$
A=\frac{50 * \emptyset}{0,19}
$$

También se realizaron gráficos para el análisis de las muestras, fueron los histogramas realizados por medio del proceso establecido con el software de visualización Mango los cuales tienen en cuenta la Moda de los datos y la Frecuencia Absoluta. Para la realización de estos gráficos se estableció una ecuación para el cálculo de la amplitud de una sección amarilla del histograma que dependerá de la porosidad de la muestra la cual muestra los datos más centralizados y más homogéneos, en cambio la sección de color verde (mayor porosidad) y rojo (menor porosidad) serán los datos que presentan mayor dispersión o heterogeneidad. Para esto se tuvo en cuenta el rango de porosidades de la muestra que presentara menor desviación típica mostrada en azul, y a esta se le dio una amplitud de 50 números CTn y aplicando la ecuación 11 se obtienen las amplitudes de la sección amarilla de cada una de las muestras (TABLA 8).

TABLA 8. Amplitudes usadas para cada muestra en los histogramas de Mango, calculadas por medio de la ecuación 11.

\begin{tabular}{clcc}
\hline N. & \multicolumn{1}{c}{ Muestras } & $\begin{array}{c}\text { Porosidad de laboratorio } \\
\text { (Boyle) }\end{array}$ & $\begin{array}{c}\text { Amplitud histograma (sección } \\
\text { amarilla) }\end{array}$ \\
\hline 1 & B-TC-PET-06 Berea & 0,1900 & 50,00 \\
2 & ALT1C Sintética & 0,1320 & 34,74 \\
3 & CD3 Sintética & 0,1800 & 47,37 \\
4 & D65B Sintética & 0,2150 & 56,58 \\
5 & RP-ALT2 Sintética & 0,1660 & 43,68 \\
6 & RPCD1 Sintética & 0,1530 & 40,26 \\
7 & LM3-1-2 Nativa Mugrosa & 0,2365 & 62,24 \\
8 & LM4-1-1 Nativa Mugrosa & 0,2414 & 63,53 \\
9 & LM4-2-5 Nativa Mugrosa & 0,2119 & 55,76 \\
\hline
\end{tabular}


El software de visualización Mango nos permite realizar unos histogramas más didácticos y con el proceso establecido serán de mayor capacidad de análisis. La proporción de los ejes para todas las muestras es igual para observar de mejor manera la diferencia entre muestras homogéneas (FIGURA 11) y heterogéneas (FIGURA 12). Nosotros manejamos un rango que involucrara todas las muestras y es de 850 a 1250 números $\mathrm{CTn}$.

La FIGURA 11 muestra la Visualización con el software Mango de histograma de la muestra 7 que verifica que la muestra 7. LM3-1-2 Nativa Mugrosa es homogénea, ya que se observa alto porcentaje de la sección amarilla que son los datos más centralizados y homogéneos teniendo en cuenta la amplitud de la muestra, y bajo porcentaje de colores verde y rojo, donde el rojo muestra datos dispersos de baja porosidad y el verde datos dispersos de alta porosidad. Además de que el grafico se encuentra apuntado y también se observa que en las vistas de la parte derecha el color amarillo que representa los datos de porosidad más centralizados son abundantes a lo largo de toda la muestra lo cual es característico de una muestra homogénea.

Histograma de la muestra 7. LM3-1-2 Nativa Mugrosa realizado en Mango
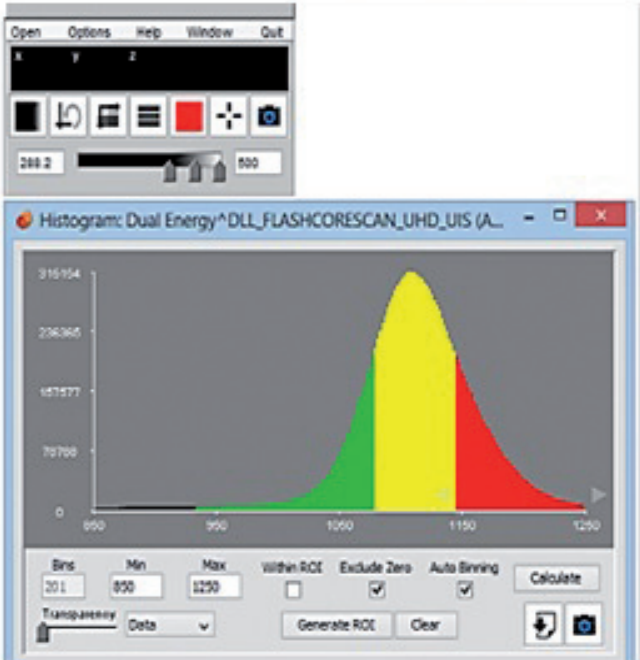
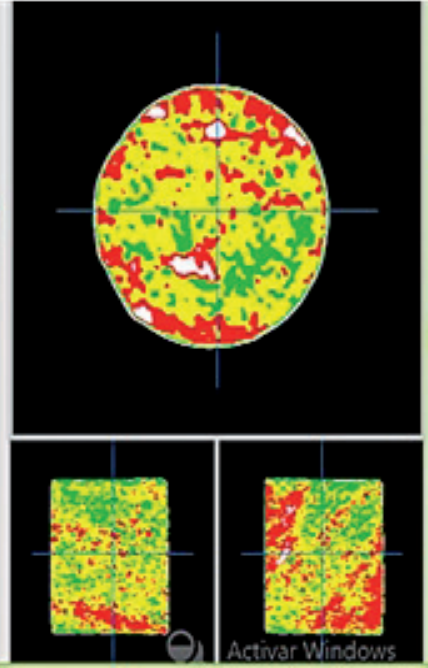

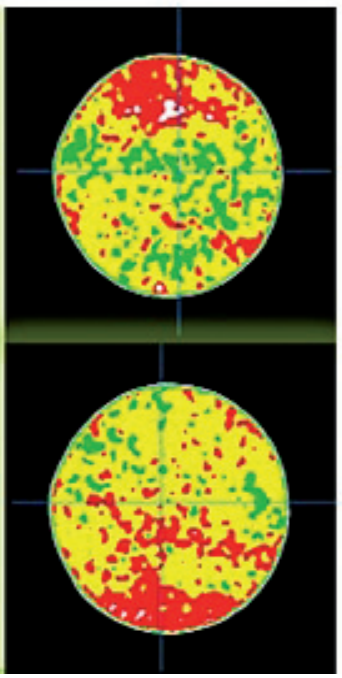

FIGURA 11. Histograma de la muestra 7 con el software Mango.

\section{Histograma de la muestra 2. ALT1C Sintética realizado en Mango.}
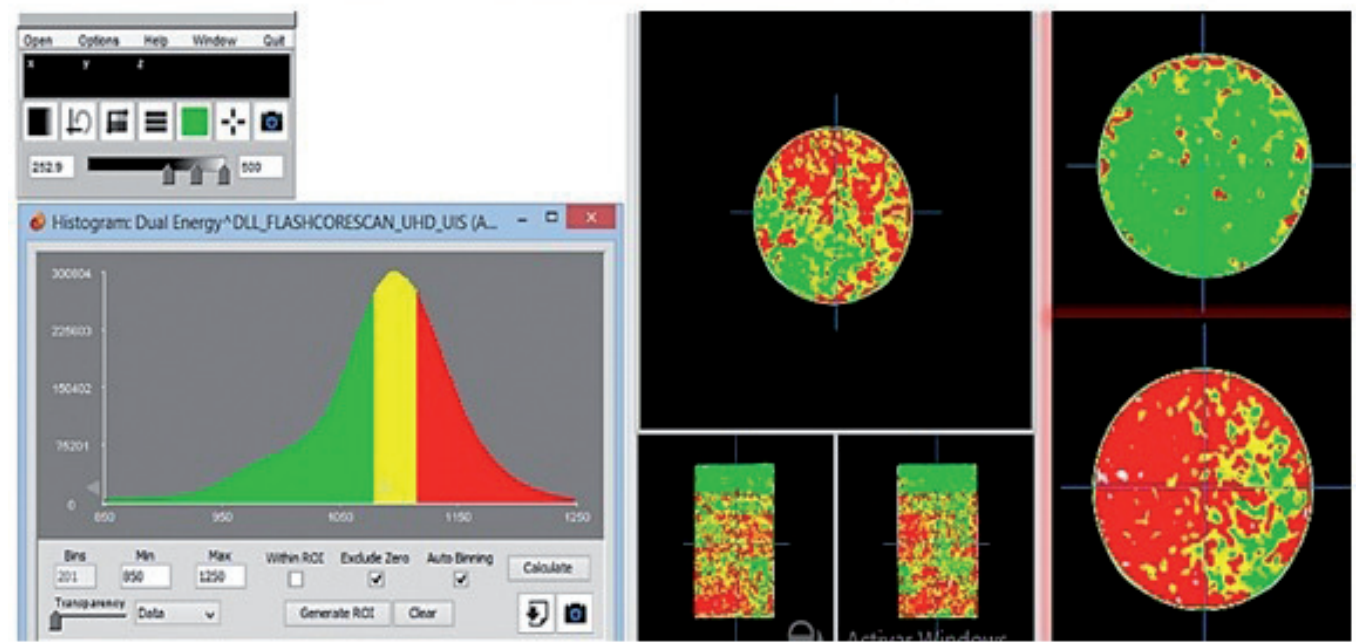

FIGURA 12. Visualización con el software Mango de histograma de la muestra 2. ALT1C Sintética. 
A partir del histograma (FIGURA 12) se verifica la heterogeneidad de la muestra, ya que se observa bajo porcentaje de la sección amarilla, o sea que tiene mala centralización de los datos y alto porcentaje de colores verde y rojo, es decir, alta dispersión o variación. Además no se encuentra apuntado, y también se observa que en las vistas de la parte derecha se observa que el color amarillo que representa los datos de porosidad más centralizados no son abundantes a lo largo de toda la muestra, y que los datos de mayor porosidad que son los de color verde se encuentran en alto porcentaje ubicados en la parte superior de la muestra, como si fueran dos formaciones diferentes en la misma muestra.

\section{CONCLUSIONES}

El uso de esta metodología permite un estudio detallado de la muestra sin necesidad de afectar su integridad física, además garantiza si la muestra se encuentra en condiciones óptimas para futuras pruebas por medio del cálculo de la heterogeneidad.

La metodología estadística aplicada a las muestras de roca tipo plug suministradas por el proyecto de "Técnicas de imágenes avanzadas" de la escuela de ingeniería de petróleos, muestra por medio del cálculo del coeficiente estadístico de heterogeneidad (CEH) los resultados que confirman de forma cuantitativa los análisis realizados cualitativamente, eliminando la subjetividad del interprete.

Se estableció un proceso adecuado para el análisis de resultados de cada una de las muestras escaneadas con tomografía computarizada de rayos X, por medio de la segmentación por colores de los histogramas realizados con el software de visualización Mango. Además los software visualización (ImageJ y Mango) permitieron el desarrollo de la investigación, puesto que facilito el manejo de las imágenes tomadas para la extracción de los coeficientes de atenuación y posteriores análisis por medio de las imágenes $2 \mathrm{D}$ y $3 \mathrm{D}$.

Las muestras B-TC-PET-06 Bérea y LM3-1-2 Nativa Mugrosa presentan buena homogeneidad, según el cálculo del coeficiente estadístico de heterogeneidad (CEH) y el análisis realizado sobre las gráficas de perfil de porosidad e histogramas, por esto se establecen como muestras representativas de la formación y se recomienda su uso para posteriores pruebas. Por el contrario los resultados obtenidos para las muestras ALT1C Sintética y RP-ALT2 Sintética manifiestan alta heterogeneidad y por lo tanto se sugiere que se descarten para cualquier prueba futura.

Por último las muestras CD3 Sintética y D65B Sintética muestran una baja heterogeneidad con buena centralización de los datos, mientras que las muestras RPCD1 Sintética, LM4-1-1 Nativa Mugrosa y LM4-25 Nativa Mugrosa revelan una heterogeneidad mayor pero aceptable para posteriores pruebas.

\section{AGRADECIMIENTOS}

Los autores agradecen a la Universidad Industrial de Santander, a la Escuela de Ingeniería de Petróleos UIS, al proyecto de tomografía "Técnicas de Imágenes Avanzadas", al Grupo de investigación de Modelamiento de Procesos de Hidrocarburos (GMPH) por la información, capacitación apoyo y colaboración recibida, al igual que los consejos y asesoramiento de varias personas involucradas en el proceso de esta investigación como el ingeniero de petróleos Andrés Felipe Ortiz Meneses. Al Grupo de Investigación en Tomografía Computarizada para Caracterización de Yacimientos (GIT).

\section{REFERENCIAS}

Bergosh, J., Marks, T., and Mitkus, A. (1985). New core analysis techniques for naturally fractured reservoirs. SPE California Reginal Meeting. Bakersfield, USA.

Descartes. Unidad Didáctica: Estadística. Distribución unidimensional. Consultado el 10 de noviembre de 2016. http://recursostic.educacion.es/descartes/ web/materiales_didacticos/unidimensional_ lbarrios/definicion_est.htm

González-Arias, A. (2012). Las matemáticas y la tomografía. Consultado el 15 de noviembre de 2017.http://www.geocities.ws/cytparatodos/ vidaytierra/tomografia/index.htm

Honarpour, M., McGee, K., Crocker, M., Maerefat, N., and Sharma, B. (1986). Detailed core description of a dolomite sample from the Upper Madison limestone Group. SPE Rocky Mountain Regional Meeting. Billings, USA.

Hunt, P., Engler, P., and Bajsarowicz, C. (1988). Computed tomography as a core analysis 
tool: Applications, instrument evaluation and image improvement techniques. Journal of Petroleum Technology, 40(9), 1203-1210. doi: 10.2118/16952-PA.

Kantzas, A., Marentette, D., and Jha, K.N. (1992). Computer-assited tomography: from qualitative visualization to quantitative core analysis. Journal of Canadian Petroleum Technology, 31(9), 48-56. doi: 10.2118/92-09-06.

MacGregor, K., Park, E., Sincock, K., and Piekenbrock, E.J. (1991). Effective unconsolidated core preservation in the arctic environment: An aid to accurate reservoir evaluation. International Arctic Technology Conference. Anchorage, Alaska.

Martínez, M. (2003). Elaboración de un algoritmo para generar mapas de heterogeneidad a partir de datos petrofísicos de un yacimiento. Tesis, Universidad Central de Venezuela, Caracas, Venezuela.

Nordtvedt, J., Ebelfort, E., Iversen, J., Sylte, A., Urkedal, H., Vatne, K.O., and Watson, A.T. (1997). Determination of three-phase relative permeabilities from displacment experiments. SPE Formation Evaluation, 12(4), 221-226.

Ortiz, A., Plata, J., Herrera, E., y Santos, N. (2015). Caracterización estática de rocas por medio de tomografía computarizada de rayos X-TAC. Revista Fuentes - El Reventón Energético, 13(1), 57-63. doi: 10.18273/revfue.v13n1-2015005.

Pérez, E.R., Juliao, T.M., y Velásquez, N.A. (2017). Técnicas y metodologías para el cálculo de porosidades asociadas a rocas generadoras. ACIPET 2017. Bogotá, Colombia.

Ramírez, J., Arboleda C., y McCollugh, C. (2008). Tomografía computarizada por rayos X: fundamentos y actualidad. Revista Ingeniería Biomédica, 2(4), 13-31.

Sánchez, D. (2015). Análisis del software ImageJ para el análisis científico de imágenes. Tesis, Escuela Técnica Superior de Ingeniería y Sistemas de Telecomunicación, Universidad Politécnica de Madrid, Madrid, España.

Siddiqui, S., and Khamees, A. (2004). Dual-energy CTscanning applications in rock characterization. SPE Annual Technical Conference and Exhibition. Houston, USA.

Software Mango. http://ric.uthscsa.edu/mango/mango. html.

Software ImageJ. https://imagej.net/Fiji/Downloads.

Wellington, S., and Vinegar, H. (1987). X-Ray Computerized Tomography. Journal of Petroleum Technology, 39(8), 885-898. doi: 10.2118/16983PA.

Withjack, E., Devier, C., and Michael, G. (2003). The role of X-Ray computed tomography in core analysis. SPE Western Regional/AAPG Pacific Section Joint Meeting. Long Beach, USA.

\begin{tabular}{c}
\hline \hline Alejandro Mendieta Penagos \\
ORCID: 0000-0002-2688-0873 \\
Luis R. Rincón Bautista \\
ORCID: 0000-0002-6428-3105 \\
Edwar Herrera Otero \\
ORCID: 0000-0003-1847-6077 \\
\hline \hline
\end{tabular}

Trabajo recibido: febrero 22 de 2018

Trabajo aceptado: septiembre 26 de 2018 